\title{
一个烟草花叶病毒株的圆二色性 和紫外照射诱发的结构变化
}

施庆洛 鲁子贤 陈作义 郑吅合

(中国科学䬧上海生物化学研究所)

描 要

本文证明在 $\mathrm{pH}$ 5-10.8 的范围里, CCGCV 的生理盐水溶液呈相同的 CD 谱. 溶液中不同盐浓度对此病毒的 $\mathrm{CD}$ 谱没有明显影响。也测定了此病毒的游离外壳蛋 白质和游离核酸的 $\mathrm{CD}$ 谱. 实验结果说明 $\mathrm{CCGCV}$ 的远紫外 $\mathrm{CD}$ 谱几乎完全由蛋白 质组份贡献. 近紫外 CD 谱可能说明病毒颗粒内 RNA 和蛋白质间有很强的相互作 用.

在 234 或 221 毫微米光照下, $\mathrm{pH} 3.1-4.8$ 时的 CCGCV 生理盐水溶液在相应波 长处的椭圆值呈现一种不寻常的变化. 光照后的病毒的 CD 谱在 $231-230$ 毫微米 和 205 毫微米附近各旺现一个强正峰. 讨论了产生此种现象的机制.

近年来, 病毒分子的构象问题已逐渐受人注意. 已有一些论文报道了对病毒的核酸和蛋 白质组份的圆二色性，但对整体病毒的圆二色性报道甚少。朱本明 ${ }^{[1]}$ 等从上海郊区大白菜中 分离到一个 TMV 新株. 本文报道此病毒及其游离组份的圆二色性, 和此病毒在等电点附近受 紫外光照时产生的大幅度 $\mathrm{CD}$ 变化.

\section{一、实 验 方 法}

\section{1. 样品}

CCGCV， TMVc 和 TSV 的制备方法见另文 ${ }^{[1,2]}$. 根据 Fraenkel-Conrat ${ }^{[3]}$ 的方法制备 CCGCV-P. CCGCV-RNA 用在皇土的存在下用酚抽提的方法制备 ${ }^{[4]}$. 样品浓度根据特定波 长的吸收率测定. CCGCV 的吸收率用 $\mathrm{A}_{200}^{16}=27.0^{[5]}$; CCGCV-P 和 CCGCV-RNA 分别用 $\mathrm{A}_{280}^{106}=13.0$, 和 $\mathrm{A}_{260}^{1 \%}=240^{[6]}$. 溶液 $\mathrm{pH}$ 为 3.1-4.8 时,样品浓度不超过 0.019 毫克/毫升. 测 定过程中,样品溶液始终是清的.

\section{2. $\mathrm{CD}$ 的测量}

$\mathrm{CD}$ 谱用 JASCO J-20 圆二色仪测定,室温 $25^{\circ} \mathrm{C}$. CD 数据用平均残基克分子椭圆值 $[\theta]$ (度. 厘米 ${ }^{2} /$ 分克分子) 表示. 光照实验时, 照射样品的光源即仪器中 450 瓦氙灯, 灯丝电流强

本文 1982 年 4 月 17 日收到.

文内所用缩写符号:

CCGCV: 中国大白菜灰心病毒；CCGCV-P：CCGCV 的游离盆白质组份：CCGCV-RNA：CGGCV 的游离核酸组

份; TMV：烟草花叶病毒；TMVc：TMV 普通株；TSV：藩茄条纹病毒；CD：圆二色性. 


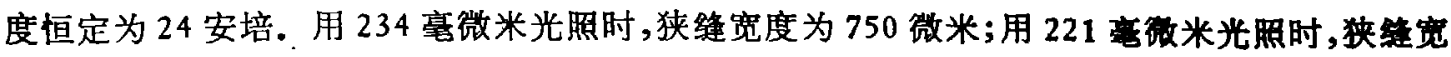
度为 1300 微米. 时间常数用 4 秒. 样品室中, 样品先避光放置 5 分钟左右, 然后受光照射. 这样做可以消除光照最初数秒钟里的极不规则的 $C D$ 变化. 受光照射的样品体积固定为 2.5 㲤升，样品池均采用光程为 1 厘米者. 样品受照射前, 于 $\mathrm{pH} 7.0,25^{\circ} \mathrm{C}$ 恒温过夜. 样品溶液 调到所需 $\mathrm{pH}$ 值后，即开始计算样品的“预保温时间”. 样品在光照实验中使用过后，即不再 重新使用.

\section{3. 差 CD 徣}

在计算差 $C D$ 谱和比较各组份的贡献时, $C D$ 数据用重量分数比椭圆值 $f[\psi]$ 表示, $f$ 为 各组份在病毒中所占的重量百分比, $[\psi]$ 为比椭圆值 (度 - 厘米 ${ }^{2} /$ 分克).

CCGCV 中蛋白质和核酸的重量比为 19:1, 所以用下列公式计算差 CD 谱:

$$
\begin{aligned}
f[\psi]_{*} & =[\psi]_{\mathrm{ccccv}}-0.95[\psi]_{\mathrm{ccccv}-\mathrm{P} .} \\
& \text { 二、实 验 结 果 }
\end{aligned}
$$

\section{CCGCV 及其组份的 CD 谱}

由于病毒的 $C D$ 值在近紫外和远紫外区相差很大, 因此分别测定这两个区域的 CD 谱. 图 1 表示 $\mathrm{CCGCV}$ 在不同 $\mathrm{pH}$ 的生理盐水溶液中的 $\mathrm{CD}$ 谱. 在一个较广的 $\mathrm{pH}$ 范围里 ( $\mathrm{pH}$ 5 10.8 ), 其 $\mathrm{CD}$ 谱是相同的: 在近紫外区出现一个 273 毫微米的正峰,在 277 毫微米, 286 毫微
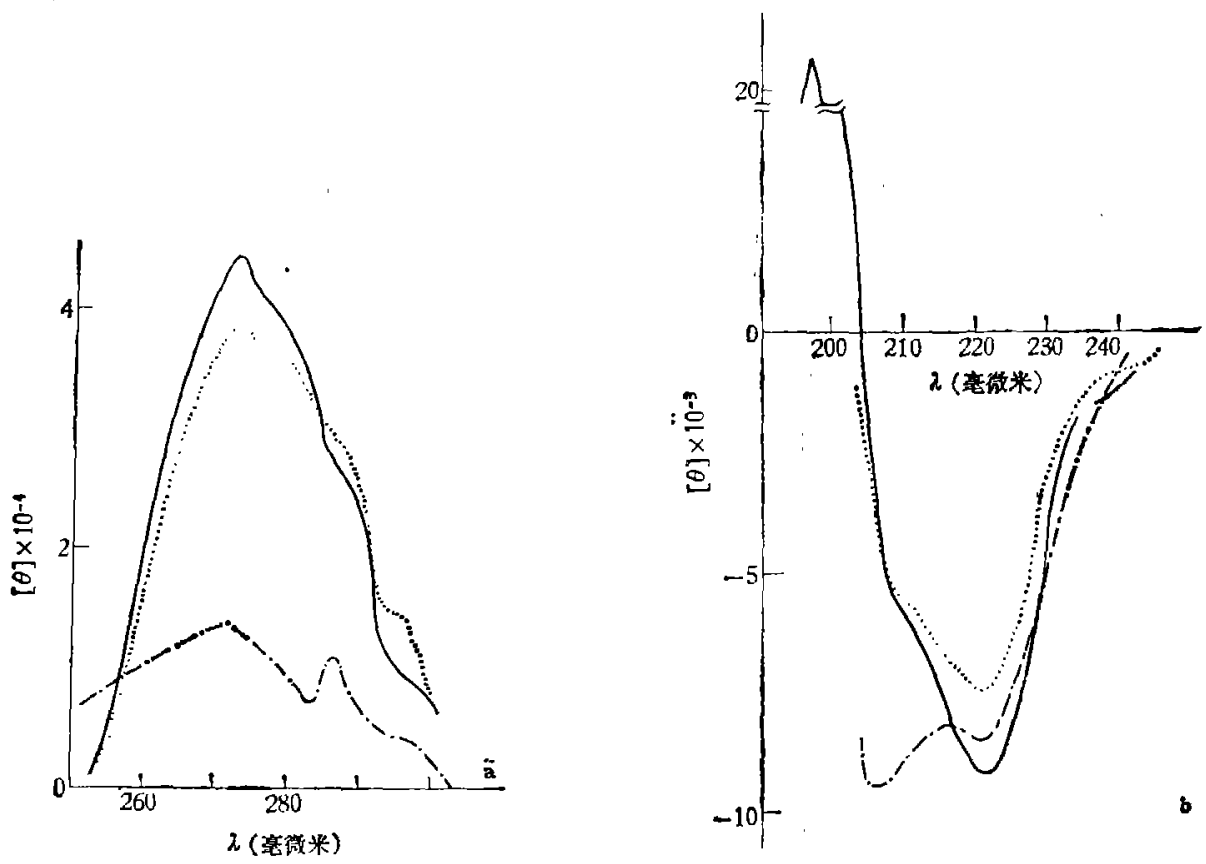

图 $1 \mathrm{CCGCV}$ 生理蓝水溶液的紫外 $\mathrm{CD}$ 谱
a. 近紫外 $\mathrm{CD}$ 谱. : pH 2.5; -....: $\mathrm{pH} 12.6$;
$\mathrm{CD}$ 数据用平均核苦酸残基克分子椭圆值表示. $25^{\circ} \mathrm{C}$

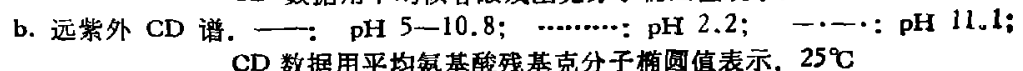


米,和 295 毫微米显示 3 个肩膀; 远紫外区显示 197 毫微米附近的强正峰, 221 毫微米的负峰, 208-209 毫微米处的肩膀. 溶液 $\mathrm{pH}$ 值下降至 3 以下后, 发现 $\mathrm{CCGCV}$ 的 $[\theta]$ 绝对值缩小. 电子显钽镜观测显示, $\mathrm{pH} 3.1$ 时，小部分 $\mathrm{CCGCV}$ 颗粒裂解. 在高 $\mathrm{pH}$ 值溶液里，此病毒的 $C D$ 谱明显不同: 其近紫外 $C D$ 值大幅度下降; 在远紫外区， $[\theta]_{221}$ 的绝对值缩小, $208-209$ 毫微米处的肩膀转变成一个负峰. 将此溶液 $\mathrm{pH}$ 值调回到近中性时, $\mathrm{CD}$ 谱并不作相应变化. 说明这种变化是不可逆的. 不同盐浓度时 $(0-7.2 \%)$, 此病毒的 CD 谱变化不大.

中性溶液中的 CCGCV-P 的 CD 谱(图 2)的测定在溶液配就后立即进行, 以避免由静置 而产生沉淀. $\mathrm{pH}<7$ 时,其溶解度很差,测定无法进行. 在生理盐水或水中, CCGCV-P 的远
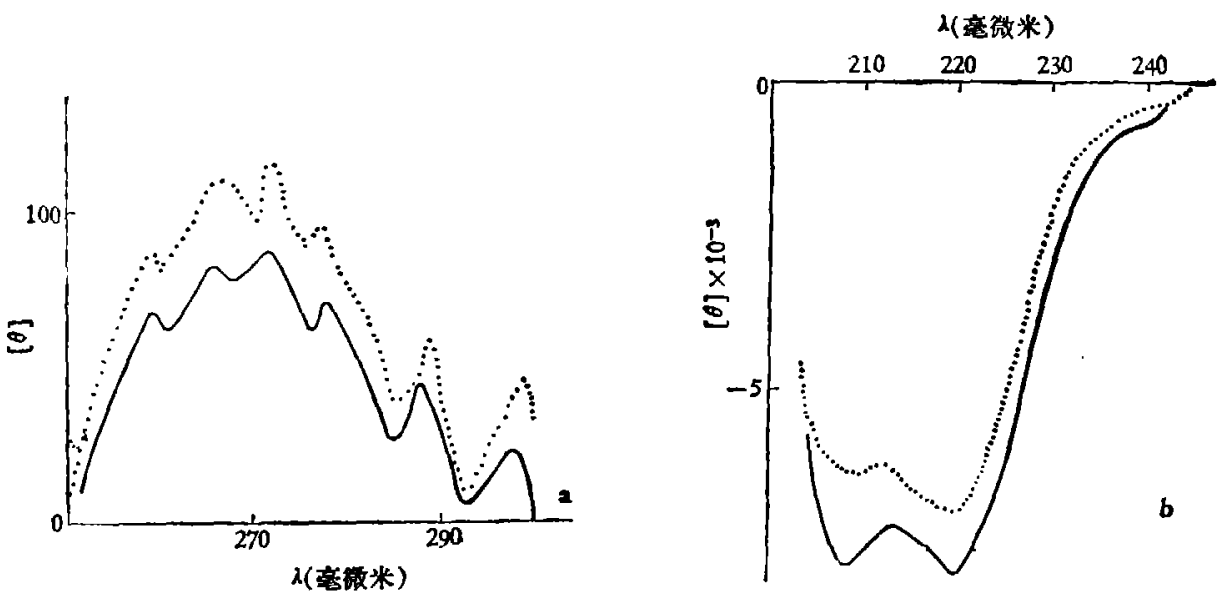

图 2 CCGCV-P 的紫外 CD 谱

(a. 近外区; b. 远紫外区. 一：在水中;

在生理盐水中, $\mathrm{pH}^{7} .1,25^{\circ} \mathrm{C}$ )

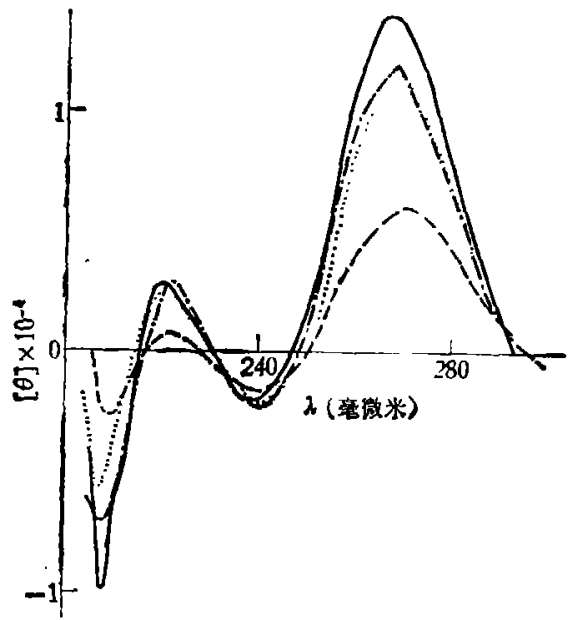

图 3 CCGCV-RNA 的紫外 CD 谱

(……... $\mathrm{pH} 7.4$, 水溶液; - - - - - : $\mathrm{pH} 7.4$, 生理盐水溶

液; 一; $\mathrm{nH} 7.4$, 含有 $0.0386 \% \operatorname{SDS}$ 的生理盐水溶液;

- - : pH 3.5, 生理盐水溶液, $25^{\circ} \mathrm{C}$ ) 
紫外 $C D$ 谱都和典型的 $\alpha$-螺旋的谱线 ${ }^{[7]}$ 相似,但与标准俧'出，其 $[\theta]_{222}$ 和 $[\theta]_{208}$ 都显得相当小. CCGCV-P 在生理盐水中的近紫外 CD 谱形和在水中的相似,两者都在 259 毫微米, 266-267 毫微米, 272 毫微米, $277-278$ 毫微米, 288-289 毫微米和 298-299 毫微米显示 6 个正峰. 但是在生理盐水中的各个峰都比在水中的相应的峰高. 对于 TMV-P 而言, 少量盐能促进其 聚合过程. 因此上述现象也许说明芳香族侧链参与了蛋白质的聚合过程.

CCGCV-RNA 的 CD 谱显示 268 毫微米的较大正峰,在 221-222 毫微米和 239-240 毫 微米是一个较小的正峰和一个较小的负峰. 208 毫微米附近还有一个较强的负峰. 在水或生 理盐水中, CCGCV-RNA 给出的 CD 谱差别不大.SDS 使它的 268 毫微米正峰升高. CCGCVRNA 的 CD 谱对 $\mathrm{pH}$ 值的变化较敏感(图 3).

从 $\mathrm{CCGCV}$ 的 $\mathrm{CD}$ 谱中减去游离蛋白质组份的贡献, 得到的近紫外差 $\mathrm{CD}$ 谱和游 离 RNA 组份的 CD 谱有很大不同 (图 4a)。比较远紫外区 $[\psi]_{\mathrm{cCGCV}}, f[\psi]_{\mathrm{ccGCV}-\mathrm{P}}$, 和 $f[\phi]_{\mathrm{CCGCV}-\mathrm{RNA}}$, 可看出蛋白质组份对病毒远紫外 $\mathrm{CD}$ 的贡献占支配地位, 核酸组分的贡献可忽 略(图 4b).
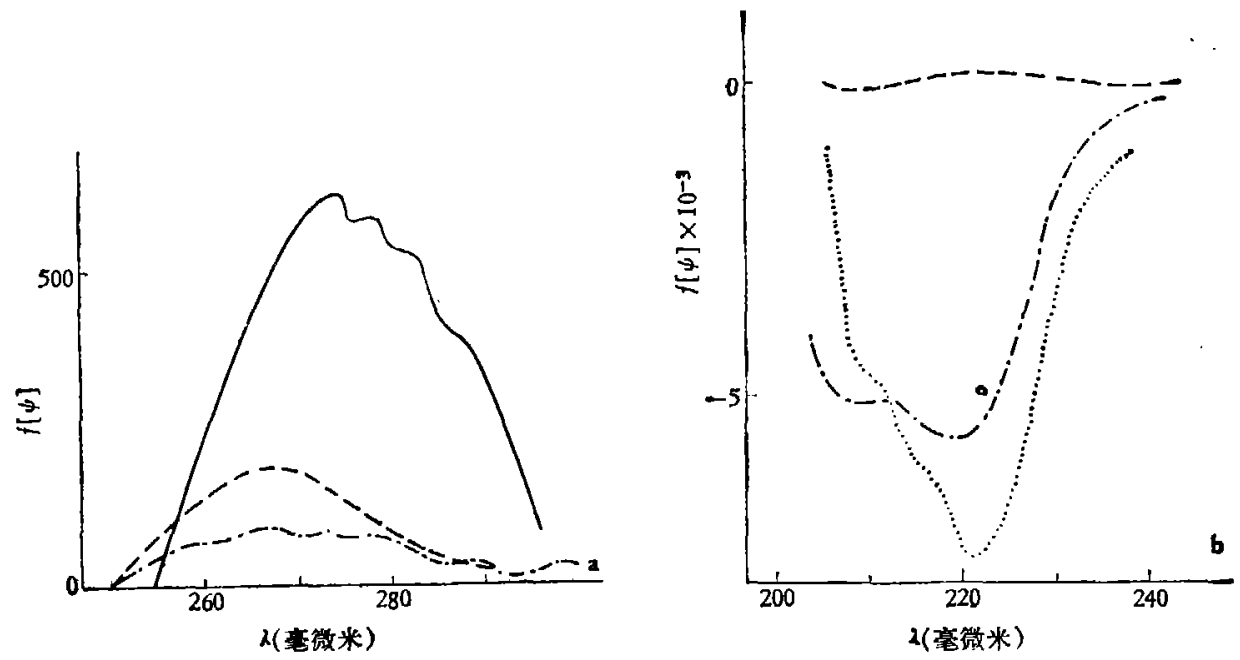

图 $4 \mathrm{CCGCV}$ 的差 $\mathrm{CD}$ 谱和各组份 $\mathrm{CD}$ 贡献比较

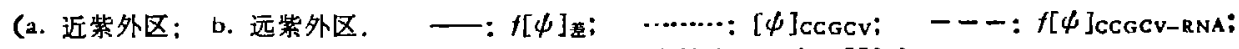

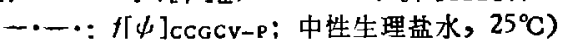

\section{2. 紫外照射桴发的 CD 变化}

初步实验发现, 在 $\mathrm{pH} 3.1$ 的生理盐水中, $\mathrm{CCGCV}$ 的 $\mathrm{CD}$ 谱随着测定过程而不断地改变, 在波长是 234 毫微米时, $[\theta]$ 的变化量最大. 所以在以后的实验中就采用 234 毫微米光照射. 在 pH 7.0 时, CCGCV 的远紫外 CD 谱的负峰在 221 毫微米, 因此同时选用 221 毫微米波长 光照射, 以观察其变化, (图 5).

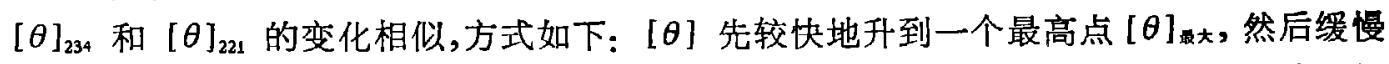
地下降, 120-150 分钟后, 下降速度更慢. 234 毫微米光照时间 [ $\theta]$ 曲线似和样品的预保 温时间有关系: 预保温时间延长有利于 $[\theta]_{\text {酒大 }}$ 的升高, 曲线升到顶峰所需时间也延长. 两 


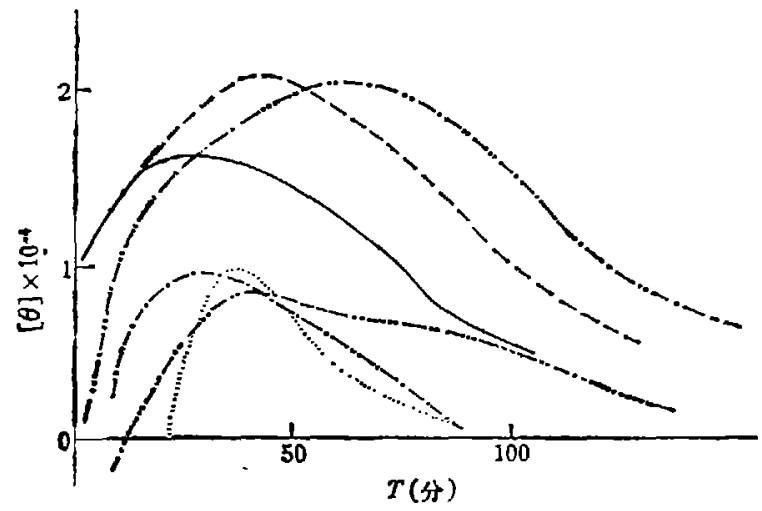

图 5 紫外照射诱发的 CCGCV 生理盐水溶液的 $\mathrm{CD}$ 变化

([ $\theta]$ 为炤射光源波长上的平均氨基酸残基克分子椭 圆值. 234 毫微米光照， $\mathrm{pH} 3.1$. - - 预保温时 间为零; ----预保温时间为 3 小时; - -...预保温时间为 6 小时. 221 毫微米光昭, $\mathrm{pH} 3.1$. -.-一氺保温时间为零; : 预保温时 间为 3 小时； -...-... 预保温时间为 6 小时)

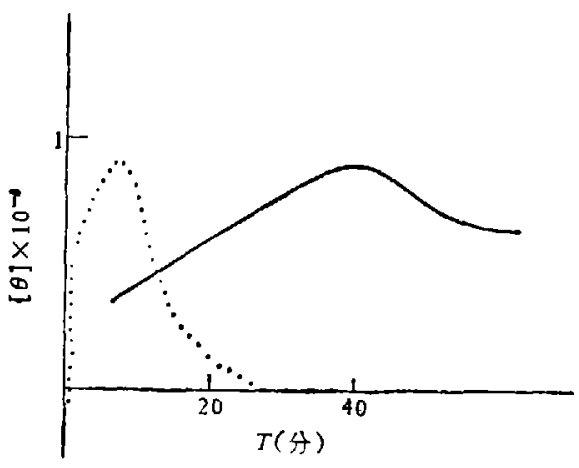

图 6 紫外炤射诱发的 TMV 株系 病毒的 $C D$ 变化

([ $\theta]$ 为平均氨基酸残基克分子椭圆值. 216 毫 微米光照, $\mathrm{pH} 3.2$, 生理盐水溶液.

—: TMVc: ......... TSV)

个 TMV 病毒株—TMVc 和 TSV 在相同条件下受 216 毫微米光照射时也产生相同的现象 (图 6).

表 1,2 显示溶液 $\mathrm{pH}$ 和盐浓度对此现象的影响. 溶液 $\mathrm{pH}<3.1$ 或 $>4.8$, 或盐浓度较 低时, 检测不到类似的 $[\theta]$ 变化. 有趣的是, $\mathrm{CCGCV}$ 的两个游离组份 - - CCGCV-P 和 CCGCV-RNA 在相同条件下并不出现此现象.

表 1 溶液 $\mathrm{pH}$ 对紫外照射诱发的 $\mathrm{CD}$ 变化的影响

\begin{tabular}{c|c|c|c|c|c|c|c}
\hline $\mathrm{pH}$ & 2.5 & 2.9 & 3.1 & 4.1 & 4.8 & 5.0 & 6.0 \\
\hline $\mathrm{CD}$ 变化情况 & - & - & + & + & + & - & - \\
\hline
\end{tabular}

光愿波长: 234 毫微米或 221 毫役米, 样品: $\mathrm{CCGCV}$ 生理盐水浴被.

表 2 盐浓度对紫外照射诱发的 CD 变化的影响

\begin{tabular}{c|c|c|c|c}
\hline 溶液中 $\mathrm{NaCl}$ 浓度 & $0.08 \%$ & $0.8 \%$ & $3.7 \%$ & $7.2 \%$ \\
\hline $\mathrm{CD}$ 变化情况 & - & + & + & + \\
\hline
\end{tabular}

光源波长: 234 毫微米或 221 毫微米。样品: CCGCV 盐水溶液, $\mathrm{pH} 3.2$.

发现样品在光照过程中某一时刻的 [ $\theta]$ 值, 在光源被遮闭 5-10 分钟后,保持不变. 所以 在光照过程中, 可以用较快速度扫描得到样品的 CD 谱（图 7,8）.234 毫微米光照时所诱发 的 CD 谱与 221 毫微米所诱发者形状相同, 但两者的椭圆值不同. 这可能反映病毒对不同波 长的光敏感性不同; 但也可能是由于仪器提供的不同波长的光的强度不同. 


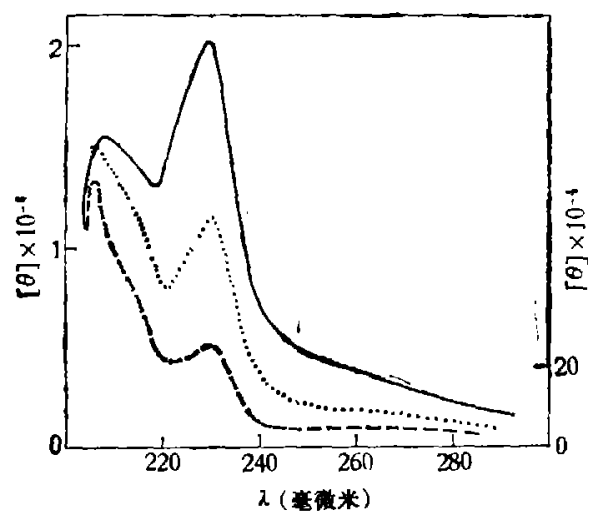

图 7 受 234 毫微米光照射后 CCGCV 生理盐水溶液的紫外 $\mathrm{CD}$ 谱

(pH 3.1, 预保温时间为 6 小时. - - 光照 59 分钟后; ……... 光照 112 分钟后; - - - 光盟 156 分钟后. 石边纵坐标表示平均核亘酸残基克分子柊圆值，左边纵 坐标表示平均矢基酸残基克分子椭圆值）

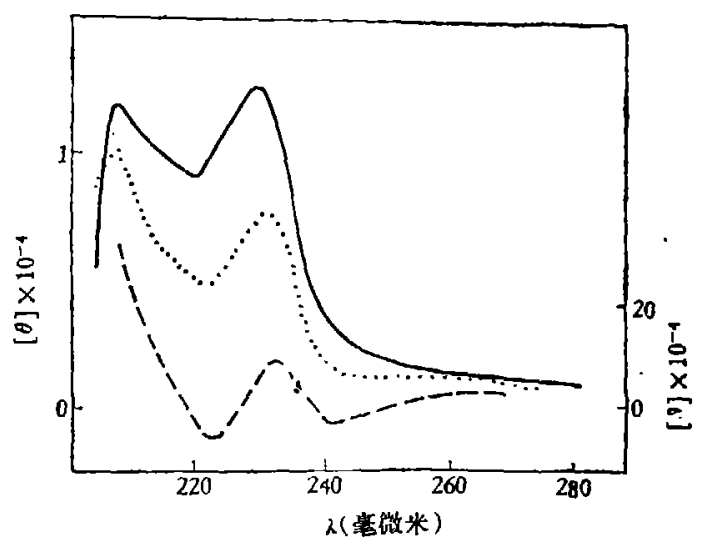

图 8 受 221 毫微米光煦后 CCGCV 生理盐水 溶液的紫外 $\mathrm{CD}$ 谱

( $\mathrm{pH} 3.1$, 预保温时间为零. 纵坐标与图 7 中的 相同. 一一: 光照 24 分钟后; …...... 光炤 64 分钟后； - - - 光照 107 分钟后)

\section{三、讨 论}

病毒颗粒较大 $(15 \times 300$ 毫微米)，在远紫外区可能存在 Duysens 吸收降和光散射等效

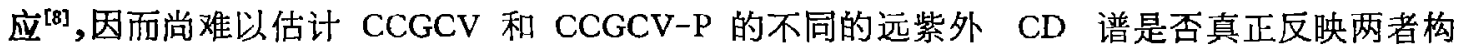
象上的差别. 但观察到在 20 倍的浓度变化和 20 倍的光程变化范围里, $\operatorname{CCGCV}$ 的 $[\theta]$ 值基 本不变,这可能表示光散射对病毒 CD 谱的影响不大.

CCGCV 和 CCGCV-P 的近紫外 CD 谱形分别和 TMV-HR 株 (Holm's ribgrass strain) 及其蛋白质组份的相似 ${ }^{[9]}$, 尤其在 297 毫微米附近. 此波长附近属色氨酸残基贡献, 推测两病 毒株的色氨酸侧链微环境可能相似。

CCGCV-RNA 中性溶液的近紫外 CD 峰在 268 毫微米左右, 和 TMV-RNA 的很相似 ${ }^{[10]}$. 此峰位置表示 RNA 分子中有较多的碱基配对 ${ }^{[1]}$. 根据 CCGCV-RNA 在酸性溶液和 SDS 溶液中的 CD 行为看, 碱基的质子化不利于 RNA 形成有序结构,而 SDS 的作用正相反.

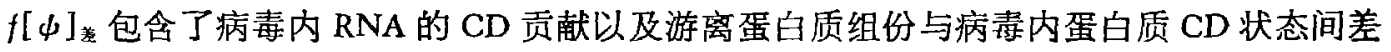
别的贡献. 由于 $[\psi]_{C C G C V}$ 的数值比 $f[\psi]_{C C G C V-P}$ 的约大 9 倍, 再考虑到其他 TMV 株系病 毒从 A-蛋白聚合成棒状颗粒时的 CD 变化情况(如 $\mathrm{TMV}-\mathrm{HR}$ 株 ${ }^{[9]}$ ), 以及一般蛋白质内芳香

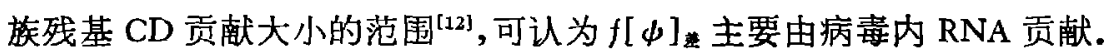

$\mathrm{X}$ 光晶体结构分析显示病瑇内 RNA 组份中不可能存在像碱基配对和碱基堆积那样的结

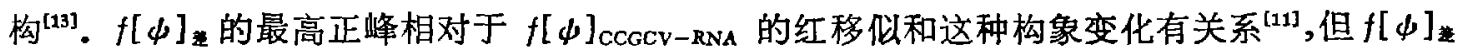
显示椭圆值大幅度提高, 这无法用构象变化解释. 因而病毒内 RNA 和游离 RNA CD 谱的

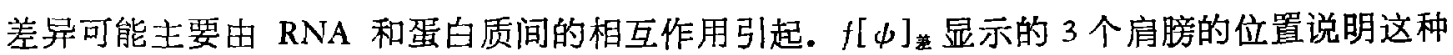
相互作用可能发生在核酸的碱基和蛋白质芳香族残基侧链间.

光照实验中, 在比色杯里的样品溶液中受光照射的只是很小一部份. 从原则上讲, 溶液中 
照射部分与未照射部分必然存在扩散,但因 10 分钟左右的“黑暗”并不影响样品已获得的 CD 值,同时考虑到病毒分子相当大,扩散现象可忽略.

光照诱发的大幅度 $\mathrm{CD}$ 变化不可能单纯由颗粒聚合度增大引起的 Duysens 吸收降和光散 射效应增大而造成. 因为 (1) 样品受光照的最初一段时间里 [ $\theta$ ] 的大幅度上升无法用此解

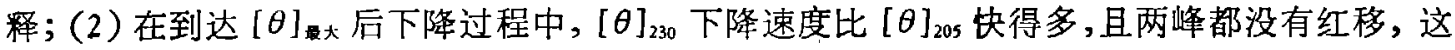
也和上述效应矛盾.

光照诱发的 $C D$ 谱与此病毒在中性溶液中的 $C D$ 谱相比,前者的近紫外 $C D$ 值比后者大 得多. 鉴于核酸组份在远紫外区的微小贡献,光照诱发的两正峰可能只与蛋白质组份有关. 因 而本文规察到的现象可能来源于光照引起的核酸和蛋白质间相互作用的加强以及蛋白质组份 构象或环境的大幅度变化.

但另一方面，光臊诱发的 $C D$ 谱和所谓 $\mathrm{PSi}$ 型 $\mathrm{CD}$ 谱很相似 ${ }^{[14]}$ ，这种类型的 $\mathrm{CD}$ 谱来源于 散射颗粒内部的非对称性有序结构. 倘若 CCGCV 的情况真是如此, 则光照的效应可能是使 病毒颗粒聚合成特定的有序结构, 而不一定和蛋白质组分的二级结构变化有关. 光照效应机 制的正确阐明,尚有待于今后的研究.

承蒙中国科学院上海生物化学研究所曹天钦教授提出有益建议,特此致谢。

\section{参考献}

[1] 朱本明等, 生物化学及生物物理学报, 13(1981),93.

[2] Leberman, R., Firology, 30(1966), 341.

[3] Fraenkel-Conrat, H., ibid., 4(1957), 1.

[4] Fraenkel-Conrat, H., ibid., 14(1961), 54.

[5] Fraenkel-Conrat, H. \& Williams, R. O., Proc. Nati. Acad. Sci. USA., 41(1955), 690.

[6] Lebeurer, S. \& Hirth, L., Virology, 38(1969), 16.

[ 7 ] Chen, Y. H., Biochemistry, 13(1974), 3350.

[8] Urry, D. W., Biochim. Biophys. Acta, 265(1972), 115.

$\lceil 9\rceil$ Dobrov, E. N., ibid., 475(1977), 623.

[10] Srinivasan, S. \& Lauffer, M. A., Archiv. Biochem. Biophys., 148 (1979), 568.

[11] Gratzer, W. B. \& Richards, E. G., Biopolymers, 10(1971), 2607.

[12] Strickland, E. H., CRC Cri. Rew. Biochem.. 2(1974), 113.

[13] Tikchonenko, T. I., in Comprehensive Virology (Ed. Fraenkei-Conrat, H. et al.), N. Y. Plenum, 5 (1975), 1.

[14] Tinoeo, I. Jr., Ann. Bew. Biophys. Bioeng., 9(1980), 107. 